Inga Staal Jenset

Universitetet i Oslo

Ida Katrine Riksaasen Hatlevik

Universitetet i Oslo

Simon Skov Fougt

Aarhus Universitet

DOI: https://doi.org/10.5617/adno.9168

\title{
Lærerutdanningens undervisningspraksiser på campus
}

Dette temanummeret retter søkelyset mot den delen av undervisningen i lærerutdanningen som foregår på campus ved utdanningsinstitusjonen. Med undervisningspraksiser siktes det både til konkrete undervisningsmetoder og til valg og organisering av kunnskapsinnhold og undervisningstilbud. Temanummeret gir derfor et bidrag til å belyse didaktikkens hva, hvordan og hvorfor for lærerutdanningen. Politikere og forskere har viet lærerutdanningen mye oppmerksomhet de seneste tiårene, både i Norden og internasjonalt (se for eksempel DarlingHammond et al., 2017). Selv om lærerutdanningene i Norge, Danmark og Sverige har ulike innretninger og til dels ulike utfordringer, har alle lands utdanninger gjennomgått store reformer det siste tiåret (KD, 2017; Regeringens proposition 2009/10:89; UFM, 2012), og forskning viser at de deler noen tilbakevendende og stabile utfordringer som er felles (se for eksempel Advisory Panel for Teacher Education, 2020; Bronäs \& Selander, 2006; Dahl et al., 2016; Finne et al., 2014). Disse utfordringene handler for en stor del om utdanningenes innhold og struktur, og mer spesifikt at det er for stor avstand mellom det undervisningstilbudet som gis og det behovet utdanningssystemet og skolene har.

Et satsingsområde i lærerutdanningen er derfor å styrke praksisopplæringen i omfang og kvalitet og å styrke partnerskapet mellom universitets- og høgskolesektoren og skolene. I Norge har dette for eksempel gitt seg utslag i økt antall praksisdager (KD, 2017), og Danmark har fått tydeligere kompetansekrav til praksisopplæringen (UFM, 2012). Forskere argumenterer imidlertid også for å styrke lærerutdanningens undervisningspraksiser på campus ved å praksisrette disse i større grad (Darling-Hammond et al., 2017; Forzani, 2014). Dette er tydelig i den norske konteksten, der det i den nasjonale strategien for kvalitet og samarbeid i lærerutdanningene, Lcrerutdanning 2025, fremheves at lærerutdanningene skal kjennetegnes av undervisning som er både forskningsbasert og praksisrelevant (KD, 2017, s. 7). Samme tendenser ses i Danmark (UFM, 2018) og til dels i Sverige (Weisdorf, 2017).

En slik praksisbasering av lærerutdanningens undervisning kan gi seg utslag i velkjente og tradisjonelle undervisningsmetoder som bruk av case (Darling- 
Hammond \& Hammerness, 2002) eller ulike typer av refleksjonsoppgaver (Beijaard \& Meijer, 2017; Hatton \& Smith, 1995). Men nyere forskning viser at også andre undervisningspraksiser gjør seg gjeldende i lærerutdanningen, som bruk av video (Gaudin \& Chaliès, 2015), fokus på «kjernepraksiser» som utgangspunkt for undervisningen (Grossman, Hammerness et al., 2009), ulike typer av forsknings- og utviklingsbaserte metoder som lesson study (Carlgren, 2012; Munthe et al., 2015) eller aksjonsforskning (Ulvik \& Riese, 2016), og ulike ordninger for mentorering (Hatlevik \& Lejonberg, 2019). Likevel vet vi lite om lærerutdanningens undervisningspraksiser, både internasjonalt (Cochran-Smith et al., 2016) og i de nordiske landene (Haugan, 2011; Jenset, 2020). Det er selvfølgelig sammensatte grunner til dette. Noen lærerutdannere har ikke forskerutdanning eller tid til forskning i sin stilling, noen identifiserer seg mer med rollen som lærerutdanner enn som lærerutdanningsforsker, og andre forsker og publiserer - men på pedagogiske, disiplinfaglige eller fagdidaktiske spørsmål som ikke er knyttet direkte til lærerutdanningen, men til skole og utdanning mer generelt (European Commission, 2013; OECD, 2019). Uansett: en bedre oversikt over lærerutdanningen som forskningsfelt kunne bidra til å «didaktisere» lærerutdanningen i større grad, og å identifisere «signature pedagogies» (Shulman, 2005) for lærerutdanningen, på samme måte som man for en stor del har gjort i klasseromsforskningen. Internasjonalt er det i økende grad fokus på «pedagogies of teacher education» (Grossman, Compton et al., 2009; McDonald et al., 2013). Lærerutdanneres rolle og lærerutdanningens didaktikk fremheves slik som avgjørende for å heve kvaliteten på lærerutdanningen, og det påpekes at lærerutdanneren må anerkjennes og støttes i dette arbeidet (OECD, 2019).

\section{Bakgrunn for temanummeret:}

\section{Fra utviklingsprosjekter til forskningspublisering i lærerutdanningen}

Temanummerets redaktører vet at det foregår mye innovativt utviklingsarbeid i lærerutdanningene i de nordiske landene, og vi har ofte sett at utfordringen er å spre og dele erfaringer og kunnskap fra slike prosjekter. Dette gjenspeiles antakelig i ovennevnte noe begrensede omfang av forskningspubliseringer på lærerutdanning som felt. Ideen til dette temanummeret oppstod i forbindelse med et oppdrag Senter for fremragende lærerutdanning (ProTed) fikk av Kunnskapsdepartementet i 2016, som innebar å lede et prosjekt som skulle finne gode eksempler på studieintensive arbeidsformer i grunnskolelærerutdanningene (STIL). Prosjektet ble ledet av ProTed-leder Doris Jorde, i tillegg til Hatlevik og Jenset, og skulle legge til rette for at fagmiljøer kunne eksperimentere med nye undervisningsmetoder, arbeidskrav, aktiviteter og studentaktive læringsformer. Utlysningen av slike utviklingsprosjekter har sjelden krav om publisering knyttet til bevilgningene, og bevilgningene er stort sett i en størrelsesorden som i liten grad gir rom for den stringens som er nødvendig for å gjennomføre, og publisere, forskning. For å stimulere deltakere i STIL-prosjektet til å publisere artikler basert på de enkelte utviklingsprosjektene, tilbød derfor ProTed som forlengelse av 
STIL-prosjektet å støtte de enkelte delprosjektene som ønsket å publisere artikler basert på datamateriale fra STIL (Hatlevik et al., 2019). I denne prosessen oppstod også tanken om et temanummer i ADNO, og tre av artiklene i dette nummeret har sitt utgangspunkt som delprosjekter i STIL (men er selvfølgelig underlagt samme rutiner og kvalitetskontroll gjennom fagfelleordningen som de andre artiklene i temanummeret).

Temanummeret ble annonsert med en åpen invitasjon 21. mars 2019, og vi mottok totalt 34 bidrag. Som i enhver fagfelleprosess kom ikke alle bidragene med i temanummeret (nummeret endte med syv artikler), men vi vil likevel benytte anledningen til å peke på at overordnet viser de opprinnelige 34 bidragene et mangfold av utviklingsprosjekter og interessante tiltak i nordisk lærerutdanning. Det er synd at ikke flere får ta del i, og lære av, disse prosjektene, og det er avgjørende for lærerutdanningen som felt at flere slike prosjekter kan dokumenteres med en kvalitet som gjør det delbart som vitenskapelig publikasjon. Ulike tiltak er iverksatt for å øke kvaliteten på, og mengden av, forskning i og på lærerutdanningen. I Norge er kravet til antall ansatte med førstekompetanse ved lærerutdanningen økt, og det er opprettet en nasjonal forskerskole for lærerutdanning (KD, 2014). I Sverige er det opprettet ulike strukturer for å øke kvaliteten på og praksisrelevansen av forskningen ved lærerutdanningsinstitusjonene (Utbildningsdepartementet, 2021), og også i Danmark peker en ekspertgruppe på behovet for at lærerutdanningens aktører skal være med på å utvikle praksisrelevant forskning (UFM, 2018). Det kan derfor være grunn til en viss optimisme med tanke på nordiske bidrag til lærerutdanningsforskningen. Likevel indikerer erfaringen med det redaksjonelle arbeidet til dette temanummeret at det trengs andre, eller ytterligere, typer av støttestrukturer og insentiver for forskningspublisering enn de som finnes i dag. Slik sett håper vi at temanummeret ikke bare er et bidrag til mer kunnskap om lærerutdanningens undervisningspraksiser og didaktiseringen av lærerutdanningen som felt, men også en påpeking av viktigheten av at lærerutdannere forsker på, og publiserer kunnskap om, lærerutdanningen.

\section{Temanummerets overordnede bidrag og implikasjoner}

Ambisjonen med temanummeret har vært å løfte frem gjennom vitenskapelig publisering erfaringer med et utvalg undervisningspraksiser i lærerutdanningen på campus. Til dette temanummeret står vi igjen med syv artikler - alle fra en norsk lærerutdanningskontekst. Disse artiklene gir viktige bidrag til forskning på lærerutdanning, og gir innsikt i en del av det gode arbeidet som foregår for å utvikle lærerutdanningens undervisningspraksiser i Norge. Overordnet bidrar artiklene med empirisk kunnskap om betydningen ulike former for støttestrukturer og sammenheng og progresjon i utdanningens læringsinnhold har for studentenes engasjement og utbytte av undervisningen. Bidragene gir på hver sine 
måter forskningsbasert kunnskap om: (i) spesifikke undervisningsmetoder $i$ lcererutdanningen, slik som inkludering av artefakter fra praksis (Jenset \& Blikstad-Balas), bruk av videorefleksjoner (Stenseth), og videoannoteringsverktøy (Nagel \& Engeness); (ii) spesifikke innholdskomponenter i lcererutdanningen, slik som interkulturell undervisning og tilpasset opplæring (Fosse \& Scheie), bærekraftdidaktikk (Ødegaard et al.), eller inkludering av manuell og digital Monte Carlo-simulering for å løse oppgaver om sannsynlighet for matematikklærere (Imenes et al.); og også (iii) mer overordnede utdanningsdesign som kan fremme lærerstudentenes læring og som har relevans for læreryrket, slik som inkluderingen av en mentorordning (Opheim \& Faye), en tverrfaglig uke (Ødegaard et al.), omvendt undervisning (flipped learning, Stenseth), eller det å legge praksis til campus (Jenset \& Blikstad-Balas).

Det metodiske bidraget fra artiklene i dette temanummeret kan tyde på at lærerutdanningsforskningen i Norge med noen unntak fremdeles er preget av småskala- og kvalitativ forskning, med mange eksempler på «self-studies», slik internasjonal forskning også påpeker (Cochran-Smith et al., 2016). Forskning på egen undervisning kan antakelig være en lettere tilgjengelig måte å forske og publisere på, og sett i lys av utfordringene med volum av forskning og publisering på lærerutdanningen som felt, kan det være viktig og riktig at lærerutdannere forsker på, og publiserer om, egen praksis. Det fremstår likevel som at det er et tydelig behov for flere og større forskningssatsinger på lærerutdanning som felt hvis vi skal drive feltet fremover.

\section{De enkelte bidragene}

Tonje Stenseth undersøker bruk av omvendt undervisning (flipped learning) og videorefleksjoner i undervisning i forskningsmetode i grunnskolelærerutdanningen ved Universitetet i Sørøst-Norge. På bakgrunn av analyser av studentenes evalueringer av en konkret studentsamling og innholdet i videorefleksjonene, argumenterer Stenseth for at omvendt undervisning bidrar til å øke studentenes egen innsats i eget læringsarbeid og muliggjøre studentsentrerte læringsomgivelser. Artikkelen viser hvordan videobaserte studentrefleksjoner kan benyttes som et konsoliderende element i studentenes forberedelser i det omvendte undervisningsdesignet, samt som ansvarliggjørende for å styrke en aktiv og deltakende studentrolle.

Ilka Nagel og Irina Engeness undersøker digitale tilbakemeldinger som førsteårsstudenter ved grunnskolelærerutdanningen ved Høgskolen i Østfold ga sine medstudenter på deres filmede muntlige presentasjoner ved hjelp av videoannoteringsverktøyet Studio. Undersøkelsen ser på hvordan dette verktøyet påvirket tilbakemeldingsprosessen. Funnene indikerer både fordeler og begrensninger ved bruk av dette verktøyet. Disse fordelene og ulempene er det viktig at den som skal ta i bruk verktøyet er oppmerksom på for at det skal fungere etter hensikten og bidra til studenters refleksjoner knyttet til undervisning. Funnene 
indikerer også at bruk av verktøyet forutsetter at studentene har god kunnskap om temaet vurdering for læring.

Inga Staal Jenset og Marte Blikstad-Balas undersøker studenters vurderinger av en nyutviklet femdagers analysepraksis i lektorutdanningen ved Universitetet i Oslo. Analysepraksis er en praksisform der studentene er på campus og der all undervisning tar utgangspunkt i en konkret case med data fra klasserommet som videoer av undervisning, intervjuer med elever og lærer, dokumenter fra timer og spørreskjemaer elevene har besvart, alt fra samme klasse. Jenset og BlikstadBalas fant at studentene opplever denne praksisformen som relevant for egen masteroppgave, og at det å analysere artefakter fra praksis er en progresjon fra tidligere praksisperioder. Videre diskuterer forfatterne hvordan studenter kan utfordres på at det å kjenne til ulike forskningsmetoder og analytiske innganger ikke bare er noe som angår forskere og masterstudenter - men alle profesjonelle lærere som skal forholde seg til forskning gjennom hele yrkeslivet.

Olav Gravir Imenes, Vibeke Bjarnø og Ove Edvard Hatlevik har undersøkt bruk av manuell og digital Monte Carlo-simulering for å løse oppgaver om sannsynlighet i gruppebesvarelser i matematikkfaget på grunnskolelærerutdanningen for 1.-7. trinn ved OsloMet - storbyuniversitetet. Forfatterne fant fordeler og ulemper ved bruk av både manuell og digital simulering, noe som indikerer at studentene kan ha nytte av å løse oppgaver ved hjelp av begge metoder. Videre peker funnene på betydningen av at underviseren inntar en aktiv rolle i forkant og underveis når det gjelder å legge til rette for studentenes læring gjennom simulering. Konkret viser studien at underviserens valg av gode og relevante oppgaver er avgjørende for at studentene opplever simuleringen som nyttig. I tillegg bør underviseren ha mulighet til å kontrollere svaret og oppdage programmeringsfeil eller utslag av tilfeldigheter under simuleringen, slik at dette ikke bidrar til forvirring hos studentene. Samlet peker studien på betydningen av at underviseren inntar en aktiv rolle i forkant og underveis når det gjelder å legge til rette for studentenes læring gjennom simulering.

Britt Oda Fosse og Janne Scheie gjør en komparativ analyse av hva et norsk (Universitetet i Oslo) og et gresk lærerutdanningsprogram vektlegger i sin undervisning om interkulturell undervisning og tilpasset opplæring. Fosse og Scheie fant at de to programmene har svært ulik tilnærming, hvor det greske har fokus på å utvikle lærerstudenters selvbevissthet ved å arbeide med kunst og kultur, mens det norske har fokus på å lære studentene effektive metoder for å sikre elevenes læring. Fosse og Scheie argumenterer for at interkulturell undervisning og tilpasset opplæring er to sider av samme sak og at disse to feltene må slås sammen i lærerutdanningen. Dette innebærer at lærerstudentene må få oppgaver som kan utvikle både selvbevissthet og interkulturell sensitivitet, samt utvikle strategier for differensiering og tilpasset opplæring. 
Marianne Ødegaard, Erik Knain, Ole Andreas Kvamme og Elin Sæther undersøker studenterfaringer fra en tverrfaglig temauke om bærekraftdidaktikk ved lektorprogrammet og praktisk-pedagogisk utdanning ved Universitetet i Oslo. Forfatterne fant at denne temauken ga studentene forståelse for hva bærekraftdidaktikk kan være, hvordan de kan gjennomføre undervisning om bærekraft i egne fag og hvordan de kan jobbe tverrfaglig. Studien diskuterer utfordringer relatert til studenters opplevelse av autensitet knyttet til tverrfaglig undervisning i bærekraft, og kompleksitet knyttet til bærekraft som fenomen og det å jobbe tverrfaglig. Artikkelen peker på at disse utfordringene forutsetter tilstrekkelig stillasbygging og forkunnskaper om tverrfaglighet for at lærerstudenter skal kunne jobbe med bærekraftspørsmål på en givende måte. I tillegg indikerer disse utfordringene behov for strukturelle endringer i lærerutdanningen.

Bente Opheim og Reidun Faye undersøker studenters erfaringer med en mentorordning i grunnskolelærerutdanningen ved Høgskulen på Vestlandet som innebærer at mentorene er masterstudenter som leder seminargrupper for førsteårsstudenter. Artikkelen bygger på intervjuer med både masterstudentene og førsteårsstudentene, og har særlig fokus på hvordan denne mentorordningen påvirket begge studentgruppenes opplevelser av mestring, tilhørighet og autonomi. Funnene i studien peker på behov for grundig planlegging, struktur og rammer for arbeidet i mentorgruppene, tydelige forventninger og beskrivelser av mentorenes oppgave, og opplæring i forkant og veiledning underveis av mentorene.

\section{Takk til fagfeller}

Redaksjonen retter en stor takk til de anonyme fagfellene som har bidratt med konstruktiv kritikk og forslag til forbedringer av de innsendte bidragene. Fagfellene tilhører institusjoner i Norge, Danmark og Finland som tilbyr lærerutdanning rettet mot grunn- eller videregående skole. 


\section{Om redaktørene for dette temanummeret}

Redaksjonen for temanummeret består av Inga Staal Jenset (UiO) og Ida Katrine Riksaasen Hatlevik (UiO). I tillegg bistår Simon Skov Fougt (Aarhus Universitet, DPU) fra den faste redaksjonen.

Inga Staal Jenset er førsteamanuensis i pedagogikk ved Universitetet i Oslo. Hun forsker på lærerutdanning og ulike typer undervisning i lærerutdanningen. Jenset er temaleder i QUINT (Quality in Nordic Teaching, Nordic Center of Excellence) for et tema som utforsker bruk av video i lærerutdanningen. Dessuten leder hun den sakkyndige komitéen for den nasjonale evalueringen av lektorutdanningene for trinn 8-13. Hun er også forskergruppeleder for Studies of Instruction across Subjects and Competences (SISCO).

Institusjonstilknytning: Institutt for lærerutdanning og skoleforskning, Universitetet i Oslo, Postboks 1099 Blindern, 0317 Oslo, Norge.

E-post: i.s.jenset@ils.uio.no

Ida Katrine Riksaasen Hatlevik er professor i pedagogikk ved Universitetet i Oslo. Hennes forskningsinteresser omfatter blant annet koherens og studiekvalitet i profesjonsutdanninger, studenters studieengasjement, utvikling av profesjonskompetanse og profesjonsidentitet, og partnerskap mellom lærerutdanningsinstitusjon og universitetsskoler. Hun er faglig leder av universitetsskolesamarbeidet ved UiO og forskergruppeleder for Teachers' Professional Development and Educational Change (TEPEC), som har et særlig fokus på forskning på lærerutdanning.

Institusjonstilknytning: Institutt for lærerutdanning og skoleforskning, Universitetet i Oslo, Postboks 1099 Blindern, 0317 Oslo, Norge.

E-post: i.k.r.hatlevik@ils.uio.no

Simon Skov Fougt er lektor i literacy ved Dansk Center for Skoleforskning ved Aarhus Universitet. Han er tidligere lektor på Læreruddannelsen ved Københavns Professionshøjskole og er medlem av den permanente redaksjonen til Acta Didactica med ansvar for blant annet lærerutdanning og dansk. Hans forskningsinteresser omfatter blant annet lesing, multimodalitet, scenariedidaktikk, læremidler og lærerprofesjonalitet.

Institusjonstilknytning: Danmarks Institut for Pædagogik og Uddannelse, Aarhus Universitet, København.

E-post: $\underline{\text { sifo@edu.au.dk }}$ 


\section{Referanser}

Advisory Panel for Teacher Education (2020). Transforming Norwegian Teacher Education: The Final Report for the International Advisory Panel for Primary and Lower Secondary Teacher Education. https://www.nokut.no/globalassets/nokut/rapporter/ua/2020/transforming-norwegianteacher-education-2020.pdf

Beijaard, D. \& Meijer, P. C. (2017). Developing the personal and professional in making a teacher identity. I D. J. Clandinin \& J. Husu (red.), The SAGE Handbook of Research on Teacher Education (s. 177-192). SAGE Publications Ltd. https://doi.org/10.4135/9781526402042

Bronäs, A. \& Selander, S. (2006). Verklighet, verklighet: teori och praktik i lärarutbildning. Stockholm: Norstedt.

Carlgren, I. (2012). The learning study as an approach for "clinical” subject matter didactic research. International Journal for Lesson and Learning Studies, 1(2), 126-139. https://doi.org/10.1108/20468251211224172

Cochran-Smith, M., Villegas, A. M., Abrams, L. W., Chávez-Moreno, L. C., Mills, T. \& Stern, R. (2016). Research on teacher preparation: Charting the landscape of a sprawling field. In D. H. Gitomer \& C. A. Bell (Eds.), Handbook of research on teaching (5th ed.) (s. 439-547). Washington, DC: American Educational Research Association.

Dahl, T., Askling, B., Heggen, K., Kulbrandstad, L. I., Lauvdal, T., Qvortrup, L., ... Thue, F. W. (2016). Om leererrollen. Oslo: Fagbokforlaget.

Darling-Hammond, L., Burns, D., Campbell, C., Goodwin, L., Hammerness, K., Low, E. L., ... Zeichner, K. M. (2017). Empowered Educators: How high performing systems shape teaching quality around the world. San Francisco, CA: Jossey-Bass.

Darling-Hammond, L. \& Hammerness, K. (2002). Toward a Pedagogy of Cases in Teacher Education. Teaching Education, 13(2), 125-135. https://doi.org/10.1080/1047621022000007549

European Commission (2013). Supporting teacher educators for better learning outcomes. https://ec.europa.eu/assets/eac/education/policy/school/doc/support-teachereducators_en.pdf

Finne, H., Mordal, S. \& Stene, T. M. (2014). Oppfatninger av studiekvalitet $i$ lererutdanningene 2013. SINTEF rapport. https://www.sintef.no/globalassets/upload/teknologi_og_samfunn/teknologiledelse/sintef_1 127901_oppfatninger-av-studiekvalitet-i-larerutdanningene-2013.pdf

Forzani, F. M. (2014). Understanding “core practices” and "practice-based” teacher education: Learning from the past. Journal of Teacher Education, 65(4), 357-368. https://doi.org/10.1177/0022487114533800

Gaudin, C. \& Chaliès, S. (2015). Video viewing in teacher education and professional development: A literature review. Educational Research Review, 16, 41-67. https://doi.org/10.1016/j.edurev.2015.06.001

Grossman, P., Compton, C., Igra, D., Ronfeldt, M., Shahan, E. \& Williamson, P. (2009). Teaching practice: A cross-professional perspective. Teachers College Record, 111(9), 2055-2100. https://tedd.org/wp-content/uploads/2014/03/Grossman-et-al-Teaching-Practice-A-CrossProfessional-Perspective-copy.pdf

Grossman, P., Hammerness, K. \& McDonald, M. (2009). Redefining teaching, re-imagining teacher education. Teachers and teaching: Theory and practice, 15(2), 273-289. https://doi.org/10.1080/13540600902875340 
Hatlevik, I. K. R., Jenset, I. S. \& Jorde, D. (2019). Studieintensive arbeidsformer ved implementering av femårige grunnskolelcererutdanninger (STIL). ProTed, Universitetet i Oslo. https://www.uv.uio.no/proted/utviklingsomrader/stil-sluttrapport-january-2019.pdf

Hatlevik, I. K. R. \& Lejonberg, E. (2019). Mentoroppfølging i lektorutdanningen: Hvordan oppfølging ved en mentor kan bidra til en god studiestart for lektorstudenter. Acta Didactica Norge, 13(1), Art. 2. https://doi.org/10.5617/adno.5485

Hatton, N. \& Smith, D. (1995). Reflection in teacher education: Towards definition and implementation. Teaching and Teacher Education, 11(1), 33-49. https://doi.org/10.1016/0742-051X(94)00012-U

Haugan, J. A. (2011). A systematic review of research regarding Norwegian general teacher education 2000-2010. Nordic Studies in Education, 31(04), 229-244. http://www.idunn.no/ts/np/2011/04/art03

Jenset, I. S. (2020). The Enactment Approach to Practice-Based Teacher Education Coursework: Expanding the Geographic Scope to Norway and Finland. Scandinavian Journal of Educational Research, 64(1), 98-117. https://doi.org/10.1080/00313831.2018.1502681

KD (2014). Lererløftet. På lag for kunnskapsskolen. Oslo: Kunnskapsdepartementet. https://www.regjeringen.no/globalassets/upload/kd/vedlegg/planer/kd_strategiskole_web.p df

KD (2017). Lcererutdanning 2025. Nasjonal strategi for kvalitet og samarbeid $i$ lærerutdanningene. Kunnskapsdepartementet. https://www.regjeringen.no/contentassets/d0c1da83bce94e2da21d5f631bbae817/kd_nasjon al-strategi-for-larerutdanningene_nett.pdf

McDonald, M., Kazemi, E. \& Kavanagh, S. S. (2013). Core practices and pedagogies of teacher education: A call for a common language and collective activity. Journal of Teacher Education, 64(5), 378-386. https://doi.org/10.1177/0022487113493807

Munthe, E., Helgevold, N., Bjuland, R. \& Aslaksen, O. H. (2015). Lesson study: I utdanning og praksis. Oslo: Cappelen Damm akademisk.

OECD (2019). A Flying Start: Improving Initial Teacher Preparation Systems. Paris: OECD Publishing. https://doi.org/10.1787/cf74e549-en

Regeringens proposition 2009/10:89. Bäst i klassen - en ny lärarutbildning. https://www.regeringen.se/49b729/contentassets/c0d91cff5e4d4223b15334ce441cd00a/bas t-i-klassen---en-ny-lararutbildning-prop.-20091089

Shulman, L. S. (2005). Signature Pedagogies in the Professions. Daedalus, 134(3), 52-59. http://www.jstor.org/stable/20027998

UFM (2012). Aftaletekst. Reform av læreruddannelsen. København: Uddannelses- og Forskningsministeriet. https://ufm.dk/lovstof/politiske-aftaler/reform-af-laereruddannelsen/reform-aflaereruddannelsen.pdf

UFM (2018). Kvalitet og relevans i lcereruddannelsen. Ekspertgruppens evaluering og vurdering af lereruddannelsen af 2013. København: Uddannelses- og Forskningsministeriet. https://ufm.dk/publikationer/2019/filer/endelig-rapport_evaluering-aflaereruddannelsen.pdf

Ulvik, M. \& Riese, H. (2016). Action research in pre-service teacher education - A neverending story promoting professional development. Professional Development in Education, 
Acta Didactica Norden

42(3), 441-457.

https://doi.org/10.1080/19415257.2014.1003089

Utbildningsdepartementet (2021). Ökad kvalitet i lärarutbildningen och fler lärare i skolan. https://www.regeringen.se/48e736/contentassets/e2180d7c973c449097dbcab00eda65b3/ok ad-kvalitet-i-lararutbildningen-och-fler-larare-i-skolan.pdf

Weisdorf, A. K. (2017). Lereruddannelsen i internationalt perspektiv. Et studie af læreruddannelserne i Norge, Sverige, Finland og Holland. Professionshøjskolen Absalon. https://www2.phabsalon.dk/fileadmin/user_upload/FU/Publikationer/Laereruddannelsen_i internationalt_perspektiv___Absalon_2017.pdf 